\section{Drs. Shir and Fitzcharles reply}

\section{To the Editor:}

We thank Dr. Sarkozi for his response to our editorial entitled "Should rheumatologists retain ownership of fibromyalgia?"1. We had hoped that our comments would stimulate thought and discussion on the issue of optimal care for patients with fibromyalgia (FM).

The issue of debate concerns our differing opinions regarding the choice of healthcare professional that is best suited to provide care for patients with FM. Dr. Sarkozi believes rheumatologists should continue to manage patients with FM, based on a personal opinion that all FM originates as a result of generalized osteoarthritis $(\mathrm{OA})$ or soft tissue rheumatism. This simplistic view of causality is put forward to rationalize the choice of the ideal treating physician. We reemphasize that the essence of our message is to examine strategies for the total care of these patients, who in addition to pain, have mood disorder, sleep abnormality, fatigue, and a multiplicity of other somatic symptoms. Therefore successful management of FM can only be achieved if all components of the syndrome are addressed, many of which are outside the scope of usual rheumatology practice. Even if Dr. Sarkozi's hypothesis is correct, we know of no treatment intervention that can be offered uniquely by a rheumatologist to manage OA of the spine or soft tissue rheumatism that will cure symptoms of FM.

Dr. Sarkozi acknowledges the complexity of pain mechanisms associated with FM, correctly criticizes the ACR criteria which address only the symptom of pain, and agrees that although this condition remains a challenge to fully understand, patients are suffering and need treatment. His opinion regarding the causation of FM is, however, based entirely on personal anecdote without any sound scientific proof. The publication of a book cannot be construed as scientific evidence. We therefore strongly refute this statement of proposed etiology for a condition that has important implications from both the patient and societal perspectives.

The choice of generalized OA as the root cause for FM is a safe one. It can be predicted with reasonable certainty that at least one radiograph or computed tomography (CT) scan will show a modicum of OA in almost any woman in her late 40 s onwards. Facet joint OA is common and occurred in $66 \%$ of all women, increasing to $89 \%$ in those over 60 years of age, in a recent ancillary study to the Framingham Heart Study which screened persons for coronary and aortic calcification by CT scans ${ }^{2}$. Facet joint OA did not, however, correlate with a complaint of pain. By adding in soft tissue rheumatism as another possible causative mechanism, one can certainly bring the $66 \%-89 \%$ of patients with OA up to $100 \%$ for an objective physical diagnosis. Further, we are unable to understand how a few localized OA nodes at the tips of the fingers in the distal interphalangeal joints is an explanation for pain experienced throughout the body. The mere presence of a finding is not sufficient justification for symptom attribution. This simplistic attribution of OA as the root cause of FM, by personal opinion, is a clear win-win situation. The physician will always be correct in declaring a diagnosis and the patient will be suitably impressed by the excellent diagnostic abilities of the physician. This magical diagnosis does not translate into effective treatment for the patient with FM. If OA is indeed the underlying cause of FM, why then do the majority of persons with OA not have symptoms of FM?

Dr. Sarkozi states that he does not believe that FM is a "true central pain syndrome," but concedes that central sensitization is an identified mechanism for pain in these patients. Central pain syndrome and central sensitization essentially describe similar processes. The statement that spontaneous pain of central sensitization cannot occur in the absence of a stimulus is incorrect. Spontaneous pain without stimulation is well documented in phantom-limb disorder, complex regional pain syndrome, postherpetic neuralgia, and burning-mouth syndrome ${ }^{3-6}$. Therefore, it is somewhat obsolete to continue to believe that pain can only occur in the setting of an identifiable physical abnormality.

Outcome in FM is not dismal. Studies from across the globe report improvement in symptoms over time. Although a study of outcome by postal questionnaire in the United States suggested continued pain and disability, publications from Australia, Mexico, and Canada have reported a more favorable outcome ${ }^{7-10}$. In a recent prospective study of patients with FM in Montreal, almost 50\% reported a clinically meaningful improvement in overall status of FM over a 3 -year observation period ${ }^{10}$. This improvement in outcome is further supported by the findings that $65 \%$ of subjects improved over a 2-year period in a community based study in England $^{11}$

There are still many gaps in our knowledge and understanding of FM. The crucial issue at this time is to identify the most ideal and adequate care for these patients. Simply ascribing a cause to explain symptoms of this complex condition does not address total care for these patients. Therefore, even with the absence of a solid understanding of causality, treatment strategies to address the major symptom components of FM are crucial. We therefore stand by our argument that a physician willing, capable, and qualified to deal with all the complexity of the symptoms of this condition will best serve the interests of the patient with FM. It is time for rheumatologists to acknowledge their limitations in caring for this complex and challenging syndrome.

YORAM SHIR, MD, Montreal General Hospital Pain Centre; MARY-ANN FITZCHARLES, MB, ChB, FRCPC, Montreal General Hospital Pain Centre, Montreal General Hospital, McGill University, and Division of Rheumatology, McGill University, Montreal, Quebec, Canada. Address correspondence to Dr. M-A. Fitzcharles, Montreal General Hospital, 1650 Cedar Avenue, Montreal, Quebec H3G 1A4, Canada.

E-mail: mary-ann.fitzcharles@muhc.mcgill.ca

\section{REFERENCES}

1. Shir Y, Fitzcharles MA. Should rheumatologists retain ownership of fibromyalgia? [editorial]. J Rheumatol 2009;36:667-70.

2. Kalichman L, Li L, Kim DH, Guermazi A, Berkin V, O’Donnell $\mathrm{CJ}$, et al. Facet joint osteoarthritis and low back pain in the community-based population. Spine 2008;33:2560-5.

3. Fields HL, Rowbotham M, Baron R. Postherpetic neuralgia: irritable nociceptors and deafferentation. Neurobiol Dis 1998;5:209-27.

4. Yeziereski RP. Pain following spinal cord injury: the clinical problem and experimental studies. Pain 1996;68:185-94.

5. Handwerker HO, Bieklein F. Complex regional pain syndrome: how to resolve the complexity? Pain 2001;94:1-6.

6. Melis M, Lobo SL, Ceneviz C, Zawawi K, Al-Badawi E, Maloney $\mathrm{G}$, et al. Atypical odontalgia: a review of the literature. Headache 2003;43:1060-74.

7. Wolfe F, Anderson J, Harkness D, Bennett RM, Caro XJ, Goldenberg DL, et al. Health status and disease severity in fibromyalgia: results of a six-center study. Arthritis Rheum 1997;40:1571-9.

8. Granges G, Zilko P, Littlejohn GO. Fibromyalgia syndrome: assessment of the severity of the condition 2 years after diagnosis. J Rheumatol 1994;21:523-9.

9. Martinez JE, Ferraz MB, Sato EI, Atra E. Fibromyalgia versus rheumatoid arthritis: a longitudinal comparison of the quality of life. J Rheumatol 1995;22:270-4.

10. Fitzcharles MA, Da Costa D, Poyhia R. A study of standard care in fibromyalgia syndrome: a favorable outcome. J Rheumatol 2003;30:154-9.

11. Macfarlane GJ, Thomas E, Papageorgious AC, Schollum J, Croft PR, Silman AJ. The natural history of chronic pain in the community: a better prognosis than in the clinic? J Rheumatol 1996;23:1617-20

J Rheumatol 2009;36:12; doi:10.3899/jrheum.090709 Personal non-commercial use only. The Journal of Rheumatology Copyright @ @ 2009. All rights reserved. 